\title{
Studies on Fruit Pectin in the Development of Tablet Formulations of Ibuprofen
}

\author{
Nausheen H Siddiqui ${ }^{2,}$, Ramla Binte Baber ${ }^{1}$, Rafi A Sultan $^{1}$, Iqbal Azhar ${ }^{1}$, Waseem Ahmed², \\ Z A Mahmood ${ }^{3}$ \\ ${ }^{1}$ Department of Pharmacognosy, Faculty of Pharmacy and Pharmaceutical sciences, University of Karachi, \\ Pakistan. \\ ${ }^{2}$ Department of Pharmacy, Benazir Bhutto Shaheed University Lyari, Karachi, Pakistan. \\ ${ }^{3}$ Colorcon Limited England.
}

\begin{abstract}
Authors' Contributions
1 Data Collection \& Processing, Data Analysis and/or Interpretation, Drafting of Manuscript. 2 Data Collection \& Processing, Drafting of Manuscript.

3 Collection \& Processing, Data Analysis and/or Interpretation.

4 \& 6 Conception \& Study Design, Critical Review.

5 Drafting of Manuscript \& Critical Review.
\end{abstract}

\begin{tabular}{l}
\hline Acknowledgement \\
\hline Article info. \\
Received: May 20, 2020 \\
Accepted: February 22, 2021 \\
\hline Funding Source: Nil \\
Conflict of Interest: Nil \\
Cite this article: Siddiqui NH, Baber RB, \\
Sultan RA, Azhar I, Ahmed W, Mahmood ZA. \\
Studies on Fruit Pectin in the Development of \\
Tablet Formulations of Ibuprofen. RADS J \\
Pharm Pharm Sci. 2020; 8(4):231-241.
\end{tabular}

*Address of Correspondence Author: naushinhs@yahoo.com

\begin{abstract}
A B S T R A C T
Background: Pectin, a naturally occurring polysaccharide is more than a food additive and has got amazing properties as a gelling agent and as a binder.

Objective: The current research entails the extraction and identification of pectin from peels of selected fruits mango (Magnifera indica) and banana (Musa paradisiaca) by direct heating and using alcohol as precipitating agent. The potential of pectin as a binding agent in tablet formulation was evaluated by screening its micromeritics and post compression properties.
\end{abstract}

Method: quadruple formulations of ibuprofen with crude peel pectin extracted from mango and banana in concentration of 50, 75, 100 and $125 \mathrm{mg}$ respectively were employed in the tablet manufacture process by wet granulation method.

Results: Successful formulation of tablet was done with the extracted pectin from the two fruit peels. The micromeritics properties showed good binding and flowing properties. An increase in concentration of pectin increased the hardness and also the dissolution of tablets up to a certain extent. The disintegration time was suitable for all formulations.

Conclusion: It was concluded that pectin extracted from mango and banana peels can be used as a super disintegrating agent in pharmaceutical formulations, where needed.

Keywords: Pectin, tablet formulation, ibuprofen, disintegration, dissolution.

\section{INTRODUCTION}

Pectin comes from the family of highly complexed matrix of polysaccharides present in the plants' cell walls and constitutes up to one third of dry cell wall substance of higher plants [1]. Grasses on the other hand, contain lesser proportion of pectic substances in their cell walls (dicots $35 \%$; grass $2-10 \%$; woody plants $5 \%$ ). Within the cell, the middle lamella of cell wall contains maximum amount of pectin and this amount gradually declines moving towards the plasma membrane of cell [2].

The literature involves direct boiling and microwave heating as the most frequently employed procedures for pectin extraction. Direct water boiling is a standard approach, which takes a couple of hours to give a satisfactory yield of pectin but may undergo thermal decomposition due to prolonged heating. Alternatively, microwave heat extraction extracts an adequate amount of pectin in minimal time. The yield is also influenced by the type of organic and inorganic 
solvents are used for extraction procedure to aid the liberation of pectin from cell wall. [3]. It is widely embraced fact that a rich fibre diet is mandatory for a better health and pectin is chief water soluble fibre of fruits and vegetables [4]. It has been demonstrated that dietary pectin and its metabolites are partly responsible for the protective effects of fruits against colonic adenocarcinoma [5]. New ecofreindly methods like use of clay has also been employed in extracting pectin in an ecofriendly procedure [6]

Binders are utilized as a means to confer cohesiveness to granules in a way that a tablet lasts unblemished after compression and the size and hardness a granule attains enhances its flow property as well. They are added to the formulation to give plasticity to a tablet and therefore strengthen the interparticle bondage capacity within a tablet [7]. To select an appropriate binder for a tablet formulation, it is statutory to have an in-depth expertise of the binder features to strengthen the tablet and also the influence of the assorted materials that comprise a tablet [8]. Most of the binders are hydrophilic and are the foremost ingredient when it comes to solid dosage form design by wet granulation. Pectin is a watersoluble plant polysaccharide that exhibits hydrophilic nature when used without conjugation and leads to the liberation of the therapeutic agent in the upper gastrointestinal tract by enzymatic degradation. To specify drug release in the colon, pectin is chemically altered to enhance their hydrophobic nature when integrated with standard hydrophobic polymers [9]. Pectin is the polymer of choice bearing potential as a vehicle for oral delivery of protein drugs that are prone to gastric enzymes and cannot cross the intestinal epithelial lining. By virtue of the modified structural conformation, pectin persists as macromolecular agglomerates in the gastric acidic $\mathrm{pH}$, while tends to dissociate and swells at neutral $\mathrm{pH}$, thus delivering the drug to colon for an appropriate absorption efficaciously [10].

The plant polysaccharides in pharmaceutical formulations certitude their stability, non-toxicity, accessibility and renewability and pectin being one of them possess numerous functions like anticholesterolemic, anti-toxic, anti-hemorrhagic and antimicrobial activities. Its demulcent action safeguards the gastric wall from being irritated [11]. The intranasal pectin-based formulations with opioid analgesics incorporated intend to provide instant pain relief including effortless and appropriate dosing and least unwanted effects [12]. In-vivo investigations conducted on the release of model compounds from matrix tablets proposed that either a low methoxy or a high methoxy pectin formulation with heedful controlled proportion of calcium provides maximal colon specificity by imparting optimal shield to a drug while it's way down to the colon and a high predisposition to the enzymatic rush. Microencapsulation technique for orally administered insulin may substantiate to be a more appealing time release drug delivery system and ensures its medical usefulness and effectiveness [13].

Amongst all prescription medicines, two-thirds of the prescribed are solid dosage forms and compressed tablets make half of these dispensed medications. Tablets are the solid unit doses which render the potential of all orally administered dosage forms for their minimum proportional inconsistency and dose precision. They are the most conventional mode of drug delivery and are exploited by mankind since medieval times [14]. Ibuprofen is the among the most frequently used over- the- counter generic in Pakistan, and more than 125 national and multinational manufacturers are ibuprofen generic formulation producers with varying composition and dosage forms [15].The current study involves screening of the seasonal fruits containing pectin Extracting the crude pectin via simple extraction procedure and to characterize their physico mechanical parameters Also to utilize the purified pectin for the development of ibuprofen tablets with post compression studies on the formulated tablets.

\section{MATERIALS AND METHODS}

\section{Selection of Fruits and Preparation}

The method used for extraction of pectin was originally described by Menon, [16]. The selected fruits used in the study were mango and banana available in the local market of Pakistan. The fruits after washing with the deionized water were peeled off and were cut into thin slices, weighed at a constant weight and used for extraction.

\section{Extraction Procedure}

Peels of fruits $(400 \mathrm{mg}$ ) were set to boil in IMS (1600 $\mathrm{ml}$ ) for 5 minutes. After boiling, IMS was decanted carefully and the peels were transferred into the mechanical blender/ homogenizer, and after adding small quantity of deionized water was subjected to 
homogenization for approximately 30 seconds to obtain a lose slurry. The slurry of fruits was transferred to beakers and placed on the Bunsen burner for boiling and carefully watched till it started boiling and continued to boil for 10 minutes. It was then taken off from the burner and allowed to cool at room temperature. On cooling, the $\mathrm{pH}$ of the slurry was recorded, and adjusted to $\mathrm{pH} 5$ using $1 \mathrm{~N} \mathrm{HCl}$ solution. The slurry was filtered to separate the peels residues using a muslin. The received filtrate was transferred to a $1000 \mathrm{ml}$ capacity beaker and precipitated with $95 \%$ Ethanol. The ratio of filtrate to ethanol was adjusted 1:3. Upon adding ethanol, cloudy precipitates were appeared which became denser and floated upwards. The precipitated pectin got separated by vacuum Buchner funnel and then confirmed by the tests and finally used in the wet granulation formulation of ibuprofen tablets.

\section{Qualitative Analysis (USP29/NF24, 2007) [17]}

The physico chemical properties were studied to investigate the function attributes of pectin include Stiff gel formation, Test with 95\% ethanol, Test with potassium hydroxide and lodine test.

\section{Ibuprofen Tablets Formulation}

The tablets were prepared by wet granulation method [16]. 25 tablets were prepared for each batch from both fruits' pectin with each tablet weighing $600 \mathrm{mg}$. The formula required to make ibuprofen tablets of 600 $\mathrm{mg}$ is directed in Table $\mathbf{1}$. The drug, binder, disintegrant and diluent in their requisite quantity were grinded and passed through sieve \# 40 to obtain uniform particles. These were then mixed together and upon addition of little quantity of water, a wet agglomerate was obtained. This agglomerate was pelletized through sieve \# 16 and coarse granules obtained were dried at $45^{\circ} \mathrm{C}$ for 1 hour. The dried granules were sieved through sieve \# 20 and uniform sized granules were obtained. Required amount of lubricant and glidant were added and the resultant granules were subsequently compressed into the tablets using the single punch rotary compression machine. Stored in airtight container, the tablets were used for further studies.

\section{Evaluation of Granules}

As per USP 32/ NF 27, 2009 prescribed methods, the granules were evaluated for the flow ability [18-19]. The test performed were Angle of repose $(\alpha)$, Bulk density ( $\rho b)$, Tapped density ( $\rho t)$, Carrs index, and Hausners ratio.
The tablets after compression were estimated for quality parameters, according to the guidelines of [20] USP 32/ NF 272009 and some non- pharmacoepial methods described below. It included Weight variation, Tablet thickness, length or diameter, tablet hardness, friability testing, disintegration test and InVitro dissolution studies.

\section{RESULTS}

The conventional hot water extraction technique was used by homogenizing the peels proceeded by extraction with deionized water at a steady $\mathrm{pH} 5$ accompanied by ethanol-based precipitation. IMS was used to breach the cell wall assisting the extraction of pectin compounds from inside, while deionized water was employed as a solubilizing solvent. The extraction procedure was run in triplicate subjecting $305 \mathrm{~g}$ of banana and $326 \mathrm{~g}$ of mango pericarp each time. A thick concentrate $(48 \mathrm{~g}$ of banana and $55 \mathrm{~g}$ of mango respectively) comprising of crude pectin was recovered from each fruit and utilized as a binder in the ibuprofen formulation. Identification tests were so performed and highlighted in Table $21 \mathrm{~N}$ hydrochloric acid was used to obtain the best yield of pectin. A stiff gel was formed on cooling when $1 \mathrm{~g}$ of pectin was heated on water bath with $9 \mathrm{ml}$ of distilled water. Translucent and gelatinous precipitates were formed when an equal volume of $95 \%$ ethanol was added to $1 \% \mathrm{w} / \mathrm{v}$ pectin sample solution. When $1 \mathrm{ml}$ of $2 \% \mathrm{w} / \mathrm{v} \mathrm{KOH}$ was added to $5 \mathrm{ml}$ of $1 \% \mathrm{w} / \mathrm{v}$ pectin sample, a transparent semi-gel was formed. On acidifying this gel using dilute $\mathrm{HCl}$ and shaken well, a voluminous, colorless gelatinous precipitates were formed, which became white and flocculent on boiling. Pectin solution forms no blue color when $0.15 \mathrm{ml}$ of iodine solution got added to $5 \mathrm{ml}$ of freshly boiled and cooled sample solution $(2 \% \mathrm{w} / \mathrm{v})$. The compressed tablets were subjected to various tests, including disintegration and dissolution tests which have been shown in Table $\mathbf{3}$ and $\mathbf{4}$ for mango and banana respectively. The best results for crude pectin at a concentration of $100 \mathrm{mg}$ were observed in formulation number $\mathrm{R} 3$ and $\mathrm{R} 7$, where disintegration time was noted as 136 secs and 105 secs respectively while dissolution period was recorded more than $78 \%$. An indirect method of measuring the powder flow is Carr's index or compressibility index (C). It is the percentage compressibility of powder. The resulting compressibility index of ibuprofen tablets from mango 
peel pectin (MPP) was ranging from 14.6 to $38 \%$. Out of these formulations R2 indicated excellent powder flow (14.63\%) while R1, R3 and R4 exhibited fair and poor powder flow respectively. Among the ibuprofen formulations from banana peel pectin (BPP), R6 indicated good powder flow, while rest of the formulations R5, R7 and R8 all exhibited fair to passable flow. The overall range of compressibility index in this case was very precise, that is, 16 to $21 \%$. Hausner's ratio can be used to predict flow attributes of powder and can be related to interparticulate abrasion. The amount of force or weight needed to break the tablet determines the mechanical strength of a tablet. Friability test measures the resistance of a tablet to attrition, that a friable tablet is subjected to mechanical erosion while handling resulting from stresses due to collisions, from manufacturing till its administration [19].In both MPP and BPP formulations, a straight relationship was found between the percentage compositions of pectin to the tablet hardness as seen in Figure $\mathbf{1}$ and . More concentration of pectin in formulations resulted in increased tablet hardness as well. From R1 to R4 the hardness achieved by mango peel pectin tablets were $5.5,6.3,7.3$ and 8.2 accordingly. Likewise, in banana peel pectin formulations the hardness achieved was 4.5, 6.6, 7.3 and 8.4, when moved from $\mathrm{R} 5$ to $\mathrm{R} 8$.

Table 1. Formulation of Ibuprofen Tablet with Different Concentrations of Pectin.

\begin{tabular}{|c|c|c|c|c|c|c|c|c|c|}
\hline \multirow[b]{2}{*}{ S.No. } & \multirow[b]{2}{*}{ Ingredients } & \multicolumn{4}{|c|}{ Mango } & \multicolumn{4}{|c|}{ Banana } \\
\hline & & $\begin{array}{c}R 1 \\
(\mathrm{mg} / \mathrm{tab} \\
)\end{array}$ & $\begin{array}{c}\mathrm{R} 2 \\
(\mathrm{mg} / \mathrm{ta} \\
\mathrm{b})\end{array}$ & $\begin{array}{c}\text { R3 } \\
(\mathrm{mg} / \mathrm{ta} \\
\mathrm{b})\end{array}$ & $\begin{array}{c}\text { R4 } \\
(\mathrm{mg} / \mathrm{ta} \\
\mathrm{b})\end{array}$ & $\begin{array}{c}\mathrm{R} 5 \\
(\mathrm{mg} / \mathrm{ta} \\
\mathrm{b})\end{array}$ & $\begin{array}{c}\mathrm{R6} \\
(\mathrm{mg} / \mathrm{ta} \\
\mathrm{b})\end{array}$ & $\begin{array}{c}\mathrm{R} 7 \\
(\mathrm{mg} / \mathrm{ta} \\
\mathrm{b})\end{array}$ & $\begin{array}{c}\mathrm{R} 8 \\
(\mathrm{mg} / \mathrm{t} \\
\mathrm{ab})\end{array}$ \\
\hline 1 & Ibuprofen & 400 & 400 & 400 & 400 & 400 & 400 & 400 & 400 \\
\hline 2 & $\begin{array}{l}\text { Microcrystalline } \\
\text { cellulose }\end{array}$ & 30 & 30 & 30 & 30 & 30 & 30 & 30 & 30 \\
\hline 3 & Pectin & 50 & 75 & 100 & 125 & 50 & 75 & 100 & 125 \\
\hline 5 & Lactose & 113 & 88 & 63 & 38 & 113 & 88 & 63 & 38 \\
\hline 6 & Talc & 5 & 5 & 5 & 5 & 5 & 5 & 5 & 5 \\
\hline \multirow[t]{2}{*}{7} & Magnesium stearate & 2 & 2 & 2 & 2 & 2 & 2 & 2 & 2 \\
\hline & Total weight & 600 & 600 & 600 & 600 & 600 & 600 & 600 & 600 \\
\hline
\end{tabular}

Where $R 1=$ Mango formulation one; $R 2$ = Mango formulation two; $R 3=$ Mango formulation three; $R 4=$ formulation four; $R 5=$ Banana formulation one; $R 6$ = Banana formulation two; $R 7=$ Banana formulation three; R8= Banana formulation four.

Table 2. Qualitative Tests for Pectin.

\begin{tabular}{|c|c|}
\hline Tests & Results \\
\hline Stiff gel test & Stiff gel formed \\
\hline $95 \%$ Ethyl alcohol test & Translucent precipitates \\
\hline $2 \%$ potassium hydroxide test & Transparent semi-gel \\
\hline lodine test & No blue color \\
\hline Litmus test & Turned blue litmus red \\
\hline
\end{tabular}


Table 3. Pre-Compression Attributes of MPP Granules.

\begin{tabular}{|c|c|c|c|c|c|}
\hline Sr. No & Parameters & R1 & R2 & R3 & R4 \\
\hline 1 & Mass $(\mathrm{gm})$ & 2.01 & 2 & 2.02 & 2 \\
\hline 2 & Bulk density $(\mathrm{g} / \mathrm{cm} 3)$ & 0.39 & 0.35 & 0.31 & 0.3 \\
\hline 3 & Tapped density $(\mathrm{g} / \mathrm{cm} 3)$ & 0.5 & 0.41 & 0.5 & 0.44 \\
\hline 4 & Bulkiness $(\mathrm{cm} / \mathrm{g})$ & 2.56 & 2.85 & 3.22 & 3.33 \\
\hline 5 & Carr's index & 22 & 14.63 & 38 & 31.81 \\
\hline 6 & Hausner's ratio & 1.28 & 1.17 & 1.61 & 1.46 \\
\hline 7 & Angle of repose $\left(\Theta^{-1}\right)$ & 30.9 & 32 & 31 & 30.5 \\
\hline
\end{tabular}

Table 4. Pre-Compression Attributes of BPP Granules.

\begin{tabular}{|c|c|c|c|c|c|}
\hline Sr. No. & Parameters & $\mathbf{R 5}$ & $\mathbf{R 6}$ & $\mathbf{R 7}$ & $\mathbf{R 8}$ \\
\hline 1 & Mass $(\mathrm{gm})$ & 2 & 2 & 2 & 2 \\
\hline 2 & Bulk density $(\mathrm{g} / \mathrm{cm} 3)$ & 0.33 & 0.4 & 0.37 & 0.34 \\
\hline 3 & Tapped density $(\mathrm{g} / \mathrm{cm} 3)$ & 0.42 & 0.48 & 0.46 & 0.43 \\
\hline 4 & Bulkiness $(\mathrm{cm} / \mathrm{g})$ & 3.03 & 2.50 & 2.70 & 2.94 \\
\hline 5 & Carr's index & 21.42 & 16.66 & 19.56 & 20.93 \\
\hline 6 & Hausner's ratio & 1.27 & 1.2 & 1.24 & 1.26 \\
\hline 7 & Angle of repose $\left(\Theta^{-1}\right)$ & 30.9 & 26.5 & 29.6 & 38.6 \\
\hline
\end{tabular}

Table 5. Post Compression Parameters of MPP Formulations.

\begin{tabular}{|c|c|c|c|c|c|c|}
\hline Sr. \# & \multicolumn{2}{|c|}{ Parameters } & Batch R1 & BatchR2 & Batch R3 & Batch R4 \\
\hline 1 & \multicolumn{2}{|c|}{ Appearance } & Round Shaped & Round Shaped & Round Shaped & Round Shaped \\
\hline 2 & Weight & $(\mathrm{mg})$ & $592(5.5)$ & $602(7.5)$ & $600(2.5)$ & $602(2.0)$ \\
\hline 3 & Thickness & $(\mathrm{mm})$ & $6.9(0.88)$ & $7(0.03)$ & $7(0.26)$ & $7.1(0.01)$ \\
\hline 4 & Diameter & $(\mathrm{mm})$ & $11.19(0.00)$ & $11.19(0.00)$ & $11.19(0.00)$ & $11.19(0.00)$ \\
\hline 5 & Hardness & $(\mathrm{kP})$ & $5.57(0.11)$ & $6.37(0.28)$ & $7.37(0.51)$ & $8.27(0.80)$ \\
\hline 6 & Friability & $(\%)$ & 0.21 & 0.17 & 0.12 & 0.09 \\
\hline 7 & \multicolumn{2}{|c|}{ Disintegration (sec) } & 120 & 130 & 136 & 180 \\
\hline 8 & Dissolution & (\%) & $72.3(0.05)$ & $73.7(0.08)$ & $79.8(0.01)$ & $66.8(0.02)$ \\
\hline
\end{tabular}

${ }^{5}$ Hardness, not less than $5 \mathrm{kP},{ }^{6}$ Friability, not more than $1 \%(0.01),{ }^{7}$ Disintegration time should be within 15 minutes, ${ }^{8}$ Dissolution must not be less than $80 \%$. 
Table 6. Post Compression Parameters of BPP Formulations (Mean (SD)).

\begin{tabular}{|c|c|c|c|c|c|}
\hline Sr. \# & Parameters & Batch R5 & Batch R6 & Batch R7 & Batch R8 \\
\hline 1 & Appearance & $\begin{array}{l}\text { Oval Biconvex } \\
\text { Shaped }\end{array}$ & $\begin{array}{l}\text { Oval Biconvex } \\
\text { Shaped }\end{array}$ & $\begin{array}{l}\text { Oval Biconvex } \\
\text { Shaped }\end{array}$ & $\begin{array}{c}\text { Oval } \\
\text { Biconvex } \\
\text { Shaped }\end{array}$ \\
\hline 2 & Weight (mg) & $599(13.0)$ & $614(5.1)$ & $601(3.6)$ & $597(4.0)$ \\
\hline 3 & Thickness & $5.2(0.05)$ & $5.2(0.02)$ & $5.1(0.05)$ & $5.1(0.05)$ \\
\hline 4 & Diameter $(\mathrm{mm})$ & $19.3(0.34)$ & $19.5(0.00)$ & $19.5(0.00)$ & $19.5(0.00)$ \\
\hline 5 & Hardness ${ }^{5}(\mathrm{kP})$ & $4.36(0.23)$ & $6.63(0.25)$ & $7.57(0.35)$ & $8.47(0.25)$ \\
\hline 6 & Friability ${ }^{6} \quad(\%)$ & 0.15 & 0.18 & 0.19 & 0.17 \\
\hline 7 & Disintegration $^{7}$ & 139 & 57 & 105 & 135 \\
\hline 8 & Dissolution $^{8} \quad(\%)$ & $68.3(0.14)$ & $69.3(0.15)$ & $78.2(0.01)$ & $59.3(0.03)$ \\
\hline
\end{tabular}

${ }^{5}$ Hardness, not less than $5 \mathrm{kP},{ }^{6}$ Friability, not more than $1 \%(0.01),{ }^{7}$ Disintegration time should be within 15 minutes, ${ }^{8}$ Dissolution must not be less than $80 \%$.

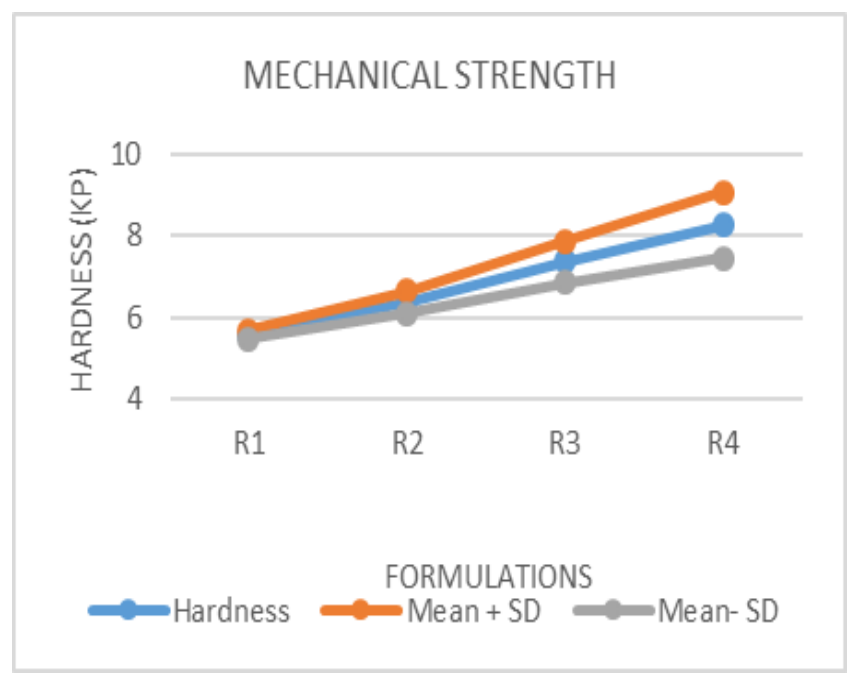

Figure 1. Comparative analysis of tablet hardness MPP.

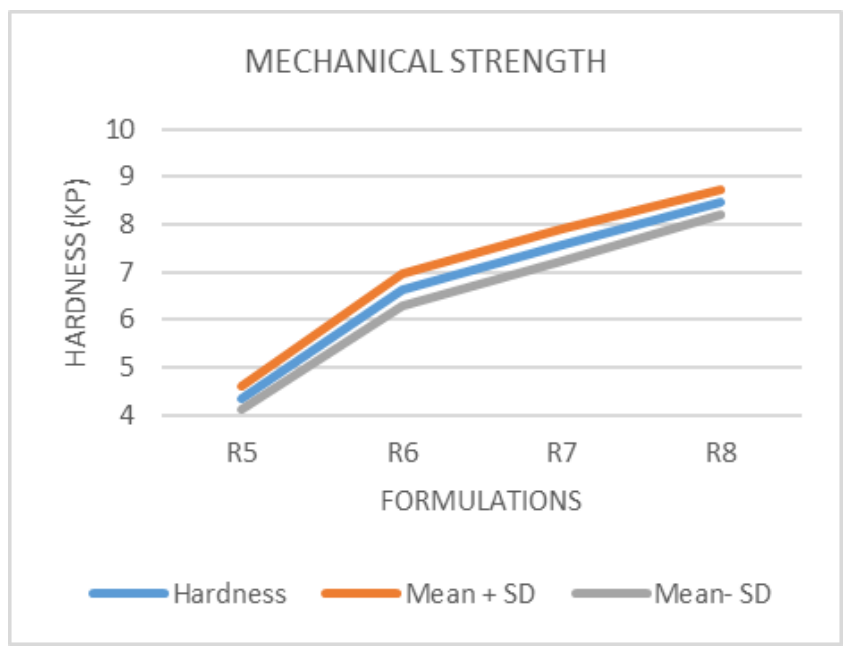

Figure 2. Comparative analysis of tablet hardness (BPP).

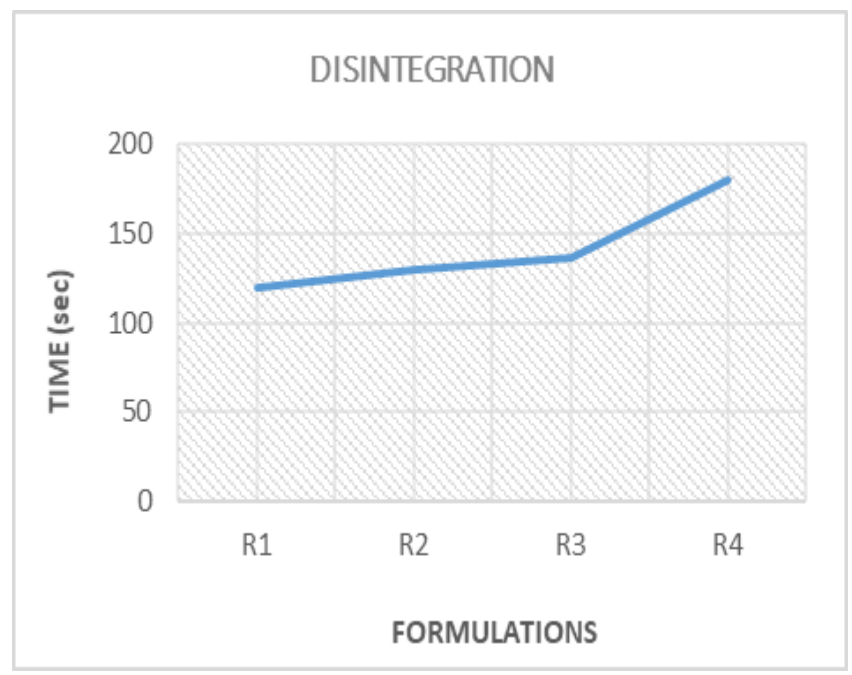

Figure 3. Comparative analysis of tablet disintegration pattern in MPP formulations.

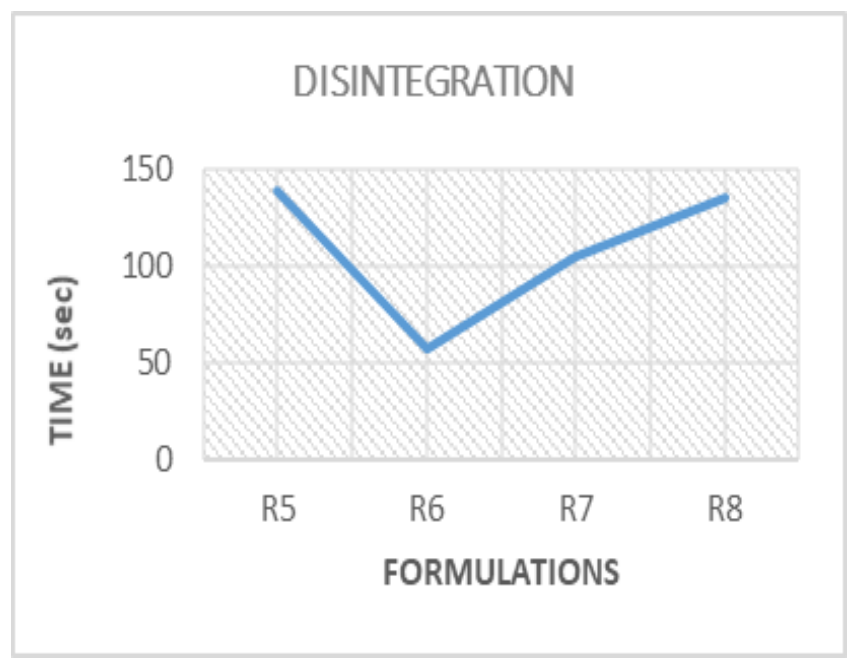

Figure 4. Comparative analysis of tablet disintegration pattern in BPP formulations. 


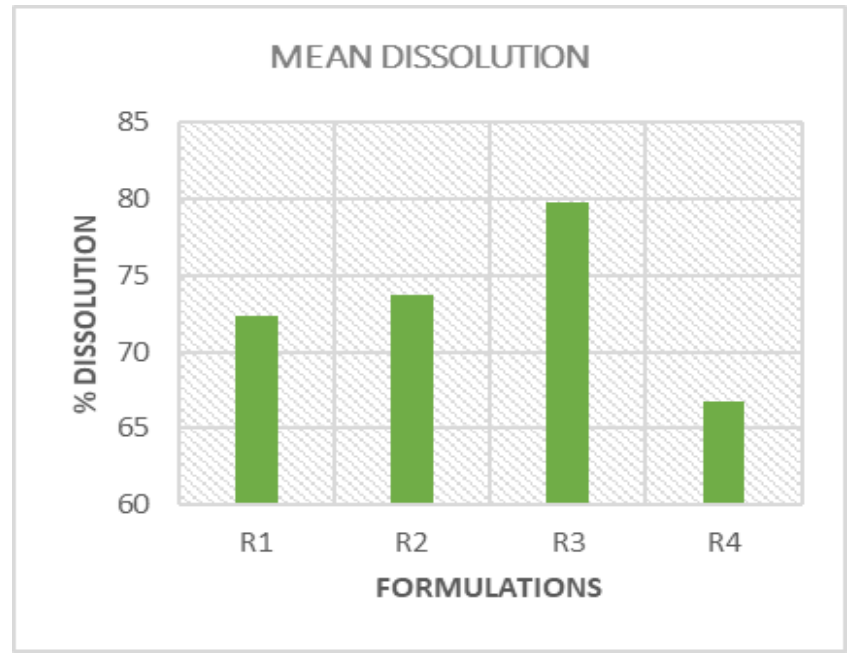

Figure 5. Mean dissolution profiles of MPP formulations.

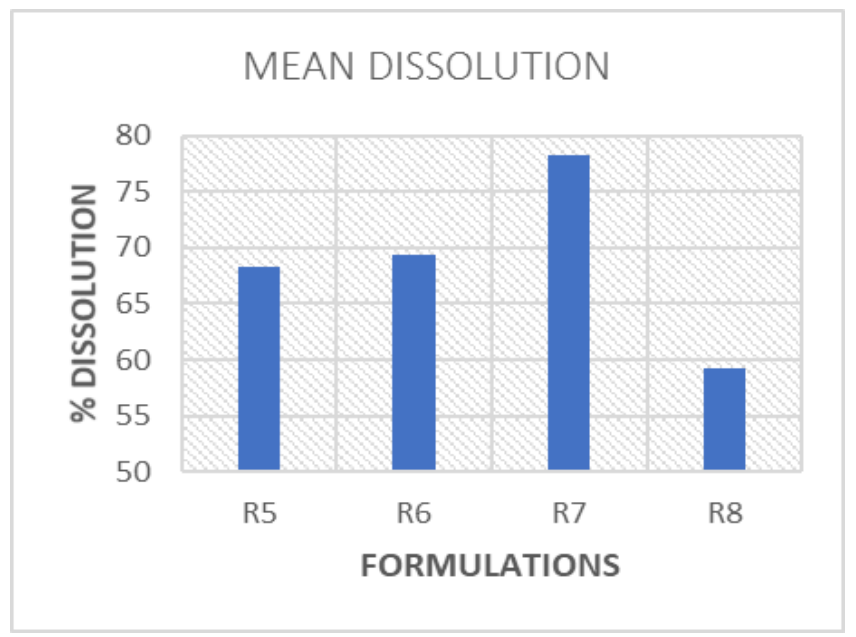

Figure 6. Mean dissolution profiles of BPP formulations.

\section{DISCUSSION}

Increased consumption of fruits and vegetables generates significant amount of organic waste. Verily, the inexpensive and easily accessible utilization of agro-food industrial waste is greatly bargainous and curtails the ecological impact of fruit waste, which would otherwise be responsible for the spread of infectious diseases. In fruits like mangoes and bananas, the discarded segment is excessive, up to $30-50 \%$ and $20 \%$ respectively [21]. The possible and most useful by- product from fruit waste that can be obtained is pectin with many dietary and commercial applications. The commercial markets cover pharmaceutical gel caps, paints, toothpaste and shampoos.
Indigenous fruits provide a very suitable source of pectin, which can be utilized in the development of pharmaceutical solid oral dosage form, especially compressed tablets. In the present study, two seasonal fruits mango and banana were studied to extract pectin and utilized the saying as a binder in ibuprofen tablet formulation. The present study plan was designed to exhibit the binding potential from Banana (Musa paradisiaca) and Mango (Mangifera indica) peel pectin as pharmaceutical adjuvants. The contemporary study focuses on the novel sources of pectin in a new system that ensures reproducibility and utility in pharmaceutical sector. The screening of fruits was done carefully keeping in mind the novelty of sources that may be utilized to extract pectin, therefore the extraction procedure and evaluation of physico mechanical parameters were discussed with regards to its application in pharmaceutical formulation, which perhaps were not reported earlier in this terrain. Commencing the extraction process, the finely cut fruit peels were immersed and boiled in IMS to breach the cell wall, assisting the extraction of pectin compounds from inside, and this characteristic feature of IMS has not been used before in the extraction of pectin. Among the mechanical procedures, homogenizing seems to be promising since it brings the maximum yield of pectin at acidic $\mathrm{pH}$, while the deionized water acted as solubilizing agent. Canteri discussed the significance of particle size reduction on total yield of pectin. This is on the grounds that reduced particle size improves protopectin release that is ultimately responsible for pectin yield when precipitated with alcohol [22]. The boiling time was limited to 10 minutes, as it has pronounced effect on overall yield of pectin and prolonged boiling on direct flame may increase the chances of degradation. Likewise, the $\mathrm{pH}$ of the extracting medium significantly effects, the lesser strength of mineral acid was used to keep the corrosive nature off and to make the procedure environment friendly. In the extraction process, [23] found that the use of $1 \mathrm{~N} \mathrm{HCl}$ gives good yield of pectin from mango peel. Another study was conducted by Z. U. Rehman who investigated the optimal extraction conditions for pectin using the mango peels and its subsequent precipitation. By soaking the peels, successfully defatted and finely pulverized into an acidic solution of sulfuric acid, he found the maximum yield of $21 \%$ [24]. Ethanol was successfully used as a precipitating agent, as it ensures the recovery of most of the pectin from the 
filtrate obtained after extraction procedure. The whole extraction regime selected for study was kept simple and reproducible, starting with IMS and homogenizing, followed by boiling the mixture, $\mathrm{pH}$ adjustment, filtration and precipitation with ethyl alcohol.

\section{Qualitative Analysis}

Aqueous solution of pectin turned blue litmus red. As discussed earlier, pectin is distinctive from other plant that are structurally alike, e.g., gums and mucilage. Therefore, the physico chemical properties of pectin were studied in order to investigate its functional attributes in pharmaceutical system, in accordance with the United States pharmacopeia (USP29/ NF24) which are tabulated in Table 2. The foremost characteristic of pectin is its ability of gel formation and the mango and banana peel extract form gel under the conditions specified. Pectic moieties are naturally acidic, and hence it turned blue litmus red. The peel extract manifested positive result for ethyl alcohol test and the translucent gelatinous precipitates formed show the divergence of peel extract from most of the plant gums. Pectin is unmistakably different from tragacanth as it formed transparent semi-gel with $2 \%$ potassium hydroxide. The extract showed negative result with iodine test, and unlike starch, it did not form any blue coloration.

The crude pectin extract from mango and banana was used in the preparation of common solid oral formulations ibuprofen as pharmaceutical adjuvants and were evaluated for physico-mechanical and micromeritics [25]. Bansal (2014) studied micromeritics of banana and discussed in the paper that banana pectin is heavy in nature and possess good flow property, so that it can be used as excipient in tablet formulation [25]. The presence of a binder in a drug-filler blend ensures the formation of tablets and granules of optimal mechanical strength. Table $\mathbf{3}$ and $\mathbf{4}$ show the micrometrics properties.

Ibuprofen was the API and crude pectin was the investigated compound for its potential use as a binder in the discussed pharmaceutical formulation. Solution binders generally, are the most effective and therefore common rationale to incorporate binding agent/ adhesive into the granules, thus forming binder-substrate granules [19]. Microcrystalline cellulose is used as a tablet disintegrant and antiadherent, where the amount in a tablet ranges from 6 $\mathrm{mg}$ to $100 \mathrm{mg}$. Lactose or milk sugar here found its use as a diluent, with amounts varying from $1 \mathrm{mg}$ to
$500 \mathrm{mg}$. Magnesium stearate and hydrated magnesium silicate (talc) here were the lubricant and glidant and/or anticaking agents respectively, while distilled water was serving as a granulating agent [26].

Bulk density or fluff density is the characteristic of the powder rather the particles, while true density or tapped density is rather the characteristic of particles and a powder can possess only a single true density. The results in mango peel pectin formulations were quite similar to that in Carr's index, with R2 having the least interparticulate friction with course granules (1.17), R1 and R4 were passable (1.28 and 1.46 respectively) whereas $\mathrm{R} 3$ was more cohesive with less free flowing characteristics (1.61). A more similar pattern was seen in ibuprofen formulations from banana peel pectin, where all of the formulations from R5 to R8 exhibited the same range of ratio 1.2 indicating 'fair to passable' powder flow, with slightly fluctuating values.

Angle of repose is the characteristic of cohesion or internal friction and estimates the flow property of powders. The angle of repose of mango peel pectin formulations came under the 'free flowing' range $\left(30^{\circ}\right.$ $\left.34^{\circ}\right)$. While angle of repose was categorized 'very free flowing' for R6 $\left(26.5^{\circ}\right)$ in banana peel pectin formulation and 'good' in R5 and R7 which came (30.9 and 29.6 respectively), Tablets were evaluated for their weight after compression, since the weight variation shows an important concern about the content uniformity and provides a guideline for consistency of tablet size. It is the fundamental quality criteria a tablet must fulfill for any pharmaceutical solid dosage form to have a constant weight and size and falls under the given limits by pharmacopeia. For this purpose, the analytical balance was used. The weight of all formulations in both the types (MPP and BPP) remained under the allowable limit $\pm 5 \%$. Thickness and diameter/ length of tablets result from the size of dye filled with powder and the pressure of punch which compresses to form a tablet. The diameter/ length and thickness of all the tablets and their weights are mentioned in Table 5 and 6 respectively.

Hardness is the analysis of a tablet withstanding fracture that a tablet is able to resist chipping or abrasion and stays intact right from its packing to its transportation till removal from the pack for administration. Though the increase in hardness had a significant effect on tablet dissolution, however, all 
formulations met the criteria of tablet hardness as described by pharmacopeia (not less than $5 \mathrm{kP}$ ). The lowest friability was observed in R4 (125 mg/tab) and R5 (50 mg/ tab) of mango and banana peel pectin respectively. The binding property of orange peel pectin was earlier studied by [27] Srivastava (2011) where a lesser amount of pectin was introduced in paracetamol tablets $(400 \mathrm{mg})$ that has shown the hardness in the range of $20-22.5 \mathrm{~N}$, with pectin quantity ranging from $10-30 \mathrm{mg}$. A similar activity was conducted by S. S. [16] where the extracted orange peel pectin was employed in ibuprofen tablets weighing $600 \mathrm{mg}$, with varying concentration of pectin within formulations $(10,20,30 \mathrm{mg})$. Hardness, friability and disintegration of all batches showed least variation and found to be lying within the pharmacoepial limits, with friability readings 0.39 , $0.29,0.19$ [16].

Disintegration of a tablet ensures the generation of large and efficacious surface area of a drug in order to promote dissolution and subsequent absorption. Dissolution followed by disintegration allows a relatively broader effective surface area of drug. An uncoated tablet must disintegrate within 15 minutes, as described by the USP. Again, a linear behavior was seen between concentrations of pectin to its disintegration time. The disintegration time of formulations from R1 to R4 turn out to be from 120 to 180 seconds (Figure 3 ), while BPP again exhibited a nonlinear behavior and the disintegration time ranged from 57 to 139 seconds (Figure 4). This pattern of disintegration may be striking with regards to its use $n$ fast dispersible tablets, where the tablet must disintegrate within 3 minutes. [28] Employed mango peel pectin (MPP) to evaluate its property as disintegrating agent in comparison to the synthetic disintegrating agent sodium starch glycolate in diclofenac sodium tablets. MPP appeared to be aiding disintegrantion, MPP can be used in fast dispersible tablets [28].

Dissolution testing is the most principal technique to evaluate the performance of the preparation under invivo conditions. The release of a therapeutic agent from solid dosage form illustrates an important mechanism to examine factors that affect the bioavailability of drug [19]. The absorption patterns for mango and banana peel pectin formulations are shown in Figure 5 and $\mathbf{6}$ respectively, where it was evident that the absorption in MPP formulations was increased up to a certain extent $(100 \mathrm{mg} / \mathrm{tab})$ and it happened to decrease. The increase in quantity of pectin so far up to $125 \mathrm{mg}$ happened to increase the tablet hardness and significantly declined in-vitro dissolution, consequently making them more friable. The pattern was obvious in BPP tablets as well, the counterproductive effect was of higher concentration of pectin on dissolution property was also recorded. A maximum dissolution up to $78 \%$ in both MPP and BPP formulations was offered by $100 \mathrm{mg}$ pectin tablets, in comparison to $50 \mathrm{mg}, 75 \mathrm{mg}$ and $125 \mathrm{mg}$. Although increasing quantity of pectin imparts more hardness to tablets but it also accounted for a decrease notably in its overall dissolution. The difference in bulk and tap densities resulted due to the presence of course and fine granules and particles and has shown a good particle distribution. Mango and banana peel pectin formulations with $75 \mathrm{mg} / \mathrm{tab}$ exhibited good flow attributes of the granules and cohesiveness, which was obvious with the Carr's index and Hausner's ratio results. Weight and size uniformity in all batches were consistent during compression whereas tablet hardness is usually required between $5-10 \mathrm{kP}$ and all formulations were within the permissible limits. Dissolution studies have shown an increase in absorption up to $100 \mathrm{mg} /$ tab followed by decline on more increase in pectin concentration and all tablets were disintegrated in less than 5 minutes. Least friability pattern was seen in $100 \mathrm{mg} /$ tab and $125 \mathrm{mg} /$ tab from mango peel pectin formulations.

\section{CONCLUSION}

The study was designed to assess the pectin obtained from seasonal fruits for its physico mechanical characterization and its application in pharmaceutical products. Pectin extract from mango (Magnifera indica) and banana (Musa paradisiaca) possess good binding property.In order to ascertain the better quality and quantity of pectin along with its applications, extensive knowledge on carbohydrate chemistry and appropriate screening of the available sources, as well as optimizing the extraction conditions are the prerequisites for developing pectin based dosage forms. In this way we can explore more sources of pectin.

\section{Author Contributions}

1 , 2, participated in the design of the study, performing the experimental work, analyzing the data, writing and editing of the manuscript. 3conceived the 
idea, designed the project. All authors reviewed and approved the final manuscript.

\section{REFERENCES}

1. Loyd A, Howar A. Ansels Pharmaceutical Dosage Forms and Drug Delivery Systems. Lippincott Williams \& Wilkins; 2014.

2. Aulton ME, Taylor K. Aultons pharmaceutics: the design and manufacture of medicines. Edinburgh: Elsevier; 2013.

3. Canteri-Schemin MH, Fertonani HCR, Waszczynskyj N, Wosiacki G. Extraction of pectin from apple pomace. Brazilian Archives of Biology and Technology. 2005;48(2):259-66.

4. Stobel CEJ, K S, Jasmin Glory KJ, Pavala MS, SK $S$, Jayanthi. KG. Extraction of Pectin from Fruit wastes-an effective method of municipal solid waste management. International Journal of Advanced Research. 2014; 2(2):936-44.

5. Online Drug Information System [Internet]. Drug Information System - DrugInfoSys.com. [cited 2002 May10]. Available from: http://www.druginfosys.com/.

6. Supriya Pratap Babar, Pectin Extraction from Orange peels by using organic clay. International Journal of Scientific Research \& Engineering Trends.2021;7(1):171-173.

7. Enauyatifard Reza, Azadbakht Mohammad, Fadakar Yousef. Assessment of ferula Gummosa gum as a binding agent in tablet formulations. Acta Poloniae Pharmaceutica - Drug Research. 2012;69(2):291-8.

8. Kertesz Zl. The pectic Substances. New York: Interscience Publishers; 1951.

9. Liu L, Fishman ML, Kost J, Hicks KB. Pectin-based systems for colon-specific drug delivery via oral route. Biomaterials. 2003;24(19):3333-43.

10. Mahida MV, Gupta MM. Immediate Release Tablet Of Antihypertensive Drug Olmesartan Medoxomile. Journal of Drug Delivery and Therapeutics. 2013;3(2).

11. Malviya Rishabha., Srivastava Pranati., Bansal Mayank., Sharma Pramod Kumar. Mango peel pectin as superdisintegrating agents. Journal of scientific and industrial research. 2010;69(9):68890.

12. Menon SS., Basavaraj BV., Bharath S., Deveswaran R., Madhavan V. Formulation and evaluation of ibuprofen tablets using orange peel pectin as binding agent. Derm Pharmacia Lettre. 2011;3:241-7.

13. Mishra RK., Banthia AK., Majeed ABA. Pectin based formulations for biomedical applications: a review. Asian J. Pharm. Clin. Res. 2012;5(4): 1-7.
14. Olano-Martin Estibaliz., Rimbach Gerald H., Gibson Glenn R., Rastall Robert A. Pectin and pectic-oligosaccharides induce apoptosis in in vitro human colonic adenocarcinoma cells. Anticancer Res, 2002; 23: (1A), 341-346.

15. Oyi Avosuahi R., Allagh TS., Olayemi Olubunmi J. Comparative binding effects of wheat, rice and maize starches in chloroquine phosphate tablet formulations. Res J Appl Sci Eng Technol,2009; 1(2):77-80.

16. Rehman ZU., Salariya AM., Habib F., Shah WH. Utilization of mango peels as a source of pectin. Journal-Chemical Society of Pakistan, 2004; 26: 73-76.

17. Ridley Brent L., O'Neill Malcolm A., Mohnen Debra. Pectins: structure, biosynthesis, and oligogalacturonide-related signaling. Phytochemistry, 2001; 57(6): 929-967.

18. Rowe RC, Sheskey PJ, Owen Siân C. Handbook of pharmaceutical excipients: editores Raymond C. Rowe, Paul J. Sheskey, Siân C. Owen. London: Pharmaceutical Press; 2006.

19. Sriamornsak, Pornsak. Application of pectin in oral drug delivery. Expert Opin Drug Delivery. 2011; 8(8): 1009-1023.

20. Srivastava Pranati., Malviya Rishabha. Sources of pectin, extraction and its applications in pharmaceutical industry-An overview. Indian J. Nat. Prod. Resour, 2011; 2(1): 10-18.

21. Srivastava Pranati.,Malviya Rishabha. Sources of pectin, extraction and its applications in pharmaceutical industry-An overview. Indian journal of natural products and resources, 2010; 2(1): 10-18.

22. Nausheen $\mathrm{H}$ Siddiqui, Azhar lqbal., Saleem Furquan., Mahmood Zafar Alam.Influence and type of inorganic acid on yield of pectin from different fruit peels and effect on sensory attribute of pudding made with extracted pectin, 2016; 5(11): 235-245

23. Thakur Beli R., Singh Rakesh K., Handa Avtar K., Rao MA. Chemistry and uses of pectin-a review. Crit. Rev. Food Sci. Nutr, 1997; 37(1): 47-73.

24. Convention USP. USP 29 NF 27: United States pharmacopeia national formulary. Supplement 1. Rockville, MD: United States Pharmacopeial Convention; 2007.

25. Convention USP. USP 32 NF 27: United States pharmacopeia national formulary. Supplement 1. Rockville, MD: United States Pharmacopeial Convention; 2009.

26. Vandamme Th F., Lenourry A., Charrueau C., Chaumeil JC. The use of polysaccharides to target drugs to the colon. Carbohydr. Polym, 2002; 48(3): 219-231. 
27. Watts Peter, Smith Alan. PecSys: in situ gelling system for optimized nasal drug delivery. Expert Opin. Drug Delivery, 2009; 6(5): 543-552.

28. Yadav Neha., Morris Gordon., Harding SE., Ang Shirley., Adams GG. Various non-injectable delivery systems for the treatment of diabetes mellitus. Endocrine, Metabolic \& Immune Disorders-Drug Targets (Formerly Current Drug Targets-Immune, Endocrine \& Metabolic Disorders), 2009; 9(1): 1-13.s.

This is an Open Access article distributed under the terms of the Creative Commons Attribution License (http://creativecommons.org/licenses/by/4.0), which permits unrestricted use, distribution, and reproduction in any medium, provided the original work is properly cited. 